\title{
Marine Pseudovibrio sp. as a Novel Source of Antimicrobials
}

\section{Susan P. Crowley ${ }^{1,2}$, Fergal O'Gara ${ }^{2,3}$, Orla O'Sullivan ${ }^{1,4}$, Paul D. Cotter ${ }^{1,4, *}$ and}

Alan D. W. Dobson ${ }^{2,5}$

1 Teagasc, Moorepark Food Research Centre, Fermoy Co. Cork, Ireland;

E-Mails: susan.crowley@teagasc.ie (S.P.C.); orla.osullivan@teagasc.ie (O.O.S.)

2 School of Microbiology, University College Cork, Western Road, Cork, Ireland;

E-Mails: f.ogara@ucc.ie (F.O.G.); a.dobson@ucc.ie (A.D.W.D.)

3 Biomerit Research Centre, University College Cork, Western Road, Cork, Ireland

4 Alimentary Pharmabiotic Centre, Biosciences Institute, University College Cork, Western Road, Cork, Ireland

5 Marine Biotechnology Centre, Environmental Research Institute, Lee Road, Cork, Ireland

* Author to whom correspondence should be addressed; E-Mail: paul.cotter@teagasc.ie; Tel.: +353-025-42694; Fax: +353-025-42340.

External Editor: Orazio Taglialatela-Scafati

Received: 25 August 2014; in revised form: 24 November 2014 / Accepted: 25 November 2014 / Published: 9 December 2014

\begin{abstract}
Antibiotic resistance among pathogenic microorganisms is becoming ever more common. Unfortunately, the development of new antibiotics which may combat resistance has decreased. Recently, however the oceans and the marine animals that reside there have received increased attention as a potential source for natural product discovery. Many marine eukaryotes interact and form close associations with microorganisms that inhabit their surfaces, many of which can inhibit the attachment, growth or survival of competitor species. It is the bioactive compounds responsible for the inhibition that is of interest to researchers on the hunt for novel bioactives. The genus Pseudovibrio has been repeatedly identified from the bacterial communities isolated from marine surfaces. In addition, antimicrobial activity assays have demonstrated significant antimicrobial producing capabilities throughout the genus. This review will describe the potency, spectrum and possible novelty of the compounds produced by these bacteria, while highlighting the capacity for this genus to produce natural antimicrobial compounds which could be employed to control undesirable bacteria in the healthcare and food production sectors.
\end{abstract}


Keywords: antimicrobial; bioactives; marine; microorganism; resistance

\section{Introduction}

Antibiotic resistance among pathogenic microorganisms is becoming ever more common. Recent data published by the Centre for Disease Control and Prevention (CDC), estimated that the number of illnesses and deaths caused by antibiotic resistance exceeded 2 million and 23,000, respectively, in the United States [1] and 25,000 deaths annually in Europe are attributed to resistant hospital infections [2]. Drug resistant pathogens are currently placing a heavy financial burden on health systems worldwide with infections due to selected multidrug-resistant bacteria in the EU estimated to result in extra health-care costs and productivity losses of at least $€ 1.5$ billion each year [3]. These worrying trends of increased multidrug resistance, has led to a call by The Infectious Disease Society of America, for the delivery of ten new antibiotic drugs by 2020 [4]. Unfortunately, however, the number of new antibiotics being developed has decreased, rather than increased, in recent years [5]. The ever reducing rate at which novel and potent antimicrobials are emerging [6] means we are becoming ever more dependent on our current arsenal of antibiotics, which are rapidly losing potency. There is an urgent need for the discovery and supply of novel and potent antimicrobials from natural resources. Nearly $10 \%$ of known biologically active natural products are of microbial origin [6], with terrestrial bacteria considered well studied when compared to marine bacteria, which have in recent years been increasingly recognised for their biotechnological potential [7]. Current estimates for the global market for Marine Biotechnology products and processes stand at $€ 2.8$ billion (2010) [8]. Not surprisingly, focus has recently shifted to the oceans as a potential source for natural product discovery. Antimicrobials derived from marine microorganisms are of particular interest due to the suite of compounds being produced [9-14]. The aim of this review is to highlight a marine-derived bacteria: Pseudovibrio spp., which have shown themselves to be producers of bioactives and propose that this genus is a novel and a relatively untapped source of antimicrobial compounds.

\section{Pseudovibrio sp.}

In recent years, interest in marine-derived Pseudovibrio has increased due to the dominance of the genus amongst host-associated microbial communities, the antimicrobial ability of the members and the potency, broad-spectrum and novelty of the compounds produced by these bacteria [15-19]. Members of this genus are of the Rhodobacteracea family, Rhodobacterales order and alphaproteobacteria class. They have been obtained from numerous marine sources such as the surfaces of tunicates [15], sea squirts [20], coral [21], seawater [22], algae [23] and from a great variety of sponges worldwide, such as Axinella corrugata, Mycale laxissima from Florida [24]; E. discophorus from Portugal [25]; Irciniidae sponges also from Portuguese waters [26]; Didiscus oxeata from Jamaica [27]; P. magna, C. aurea, M. microsigmato from Brazil [28]; A. dissimilis, Polymastia boletiformis and H. simulans from Ireland [12], S. carnosus, Leucosolenia sp. from Lough Hyne, Ireland and Amphilectus fucorum, Eurypon major also from Irish coastal waters [29]. 


\subsection{Characterisation of the Genus Pseudovibrio}

Even though the marine genus Pseudovibrio has been isolated throughout the marine environment, it was described for the first time only ten years ago. To date, four species have been described, i.e., $P$. denitrificans, $P$. ascidiaceicola, $P$. japonicas and $P$. axinellae sp. nov. The first strain of the genus Pseudovibrio to be identified, a P. denitrificans isolate, was sourced from coastal seawater in 2004 [22]. More specifically, Shieh and colleagues isolated two denitrifying strains designated DN34T and DN33, from sea-water samples collected in Nanwan Bay, Kenting National Park, Taiwan which were named Pseudovibrio gen. nov. Characteristics associated with this species can be seen in Table 1 [22]. In 2006, based on the results of phylogenetic and phenotypic analyses of two strains isolated from ascidians (sea squirts), a novel species, $P$. ascidiaceicola sp. nov. was proposed [20]. In addition to the results in Table 1 , tests for $\beta$-glucosidase, arginine dihydrolase and urease are positive. Indole is produced from tryptophan and gelatin and aesculin is hydrolysed [20]. Pseudovibrio japonicas strain WSF2T was isolated in 2007, from surface seawater off the coastline of the Boso Peninsula, Japan, and examined [30]. Tests in addition to those outlined in Table 1 also yielded positive results for alkaline phosphatase, esterase (C4), esterase lipase (C8), leucine arylamidase, valine arylamidase, trypsin, acid phosphatase, naphthol-AS-BI-phosphohydrolase and $\beta$-galactosidase [30]. More recently in 2013, O' Halloran et al. [31], described strain Ad2T which, on the basis of phylogenetic analysis, DNA-DNA hybridization and differential phenotypic characteristics, was proposed as the type strain of a novel species, for which the name Pseudovibrio axinellae sp. nov. was proposed. Tests in addition to those mentioned in Table 1 revealed that aesculin, casein, DNA and gelatin are hydrolysed, while starch is not [31].

Table 1. General characteristics of $P$. denitrificans, $P$. ascidiaceicola, $P$. japonicas and $P$. axinellae sp. nov.

\begin{tabular}{|c|c|c|c|c|}
\hline Characteristics & P. denitrificans & P. ascidiaceicola & P. japonicas & $P$. axinellae \\
\hline Gram reaction & Negative & Negative & Negative & Negative \\
\hline Oxidase & Positive & Positive & Positive & Positive \\
\hline Catalase & Positive & Positive & Positive & Positive \\
\hline Cell shape & $\begin{array}{c}\text { Straight/curved rod } \\
\text { (exponential-early } \\
\text { stationary phase) }\end{array}$ & $\begin{array}{l}\text { Straight/curved rod } \\
\text { (exponential-early } \\
\text { stationary phase) } \\
\text { Predominantly cocci } \\
\text { (late stationary phase) }\end{array}$ & Rod shaped & Rod shaped \\
\hline $\begin{array}{l}\text { Aerobic/ } \\
\text { anaerobic }\end{array}$ & $\begin{array}{c}\text { Facultatively } \\
\text { anaerobic }\end{array}$ & $\begin{array}{c}\text { Facultatively } \\
\text { anaerobic }\end{array}$ & Facultatively anaerobic & $\begin{array}{c}\text { Facultatively } \\
\text { anaerobic }\end{array}$ \\
\hline Motile & $\begin{array}{c}\text { Lateral or } \\
\text { subpolar flagella }\end{array}$ & Subpolar flagella & $\begin{array}{c}\text { Lateral or } \\
\text { subpolar flagella }\end{array}$ & Subpolar flagella \\
\hline $\begin{array}{l}\text { Temperature } \\
\text { tolerances }\end{array}$ & $\begin{array}{c}\text { Grow at } 20^{\circ} \mathrm{C}-35^{\circ} \mathrm{C} \\
\text { but not at } 4{ }^{\circ} \mathrm{C} \\
\text { or } 45^{\circ} \mathrm{C}\end{array}$ & Grow at $10^{\circ} \mathrm{C}-30^{\circ} \mathrm{C}$ & $\begin{array}{c}\text { Grow at } 15^{\circ} \mathrm{C}-30{ }^{\circ} \mathrm{C} \text { but } \\
\text { not at } 8{ }^{\circ} \mathrm{C} \text { or } 35^{\circ} \mathrm{C}\end{array}$ & $\begin{array}{c}\text { Grow at } \\
10^{\circ} \mathrm{C}-30^{\circ} \mathrm{C}\end{array}$ \\
\hline Halophilic & $\begin{array}{c}\text { Grow at } \\
2 \%-6 \% \mathrm{NaCl}\end{array}$ & $\begin{array}{c}\text { Grow at } \\
3 \%-5 \% \mathrm{NaCl}\end{array}$ & $\begin{array}{c}\text { Grow at } \\
1 \%-6 \% \mathrm{NaCl}\end{array}$ & $\begin{array}{c}\text { Grow at } \\
2 \%-4 \% \mathrm{NaCl}\end{array}$ \\
\hline
\end{tabular}


Table 1. Cont.

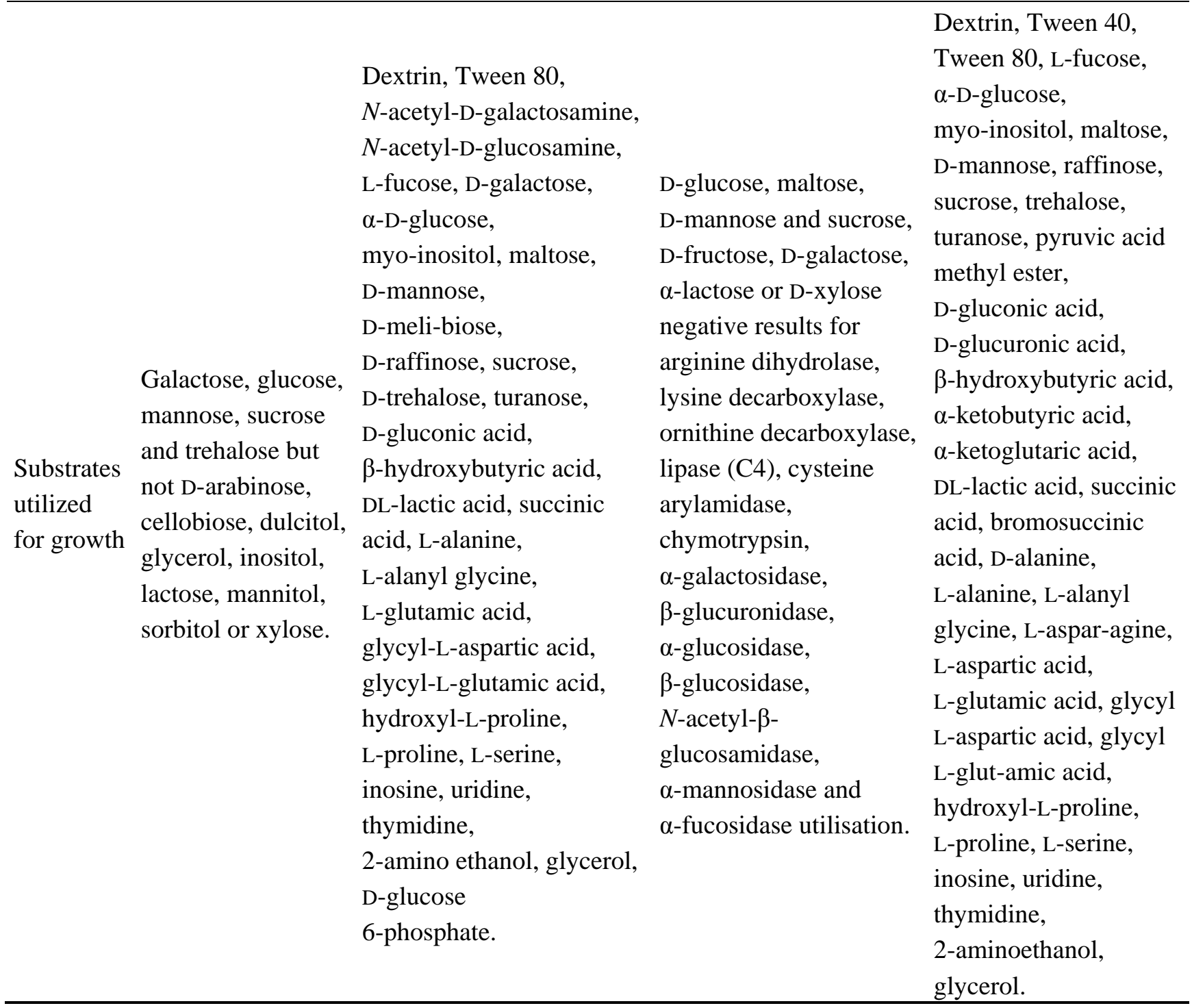

\subsection{Bioactivity of the genus Pseudovibrio}

The most commercially significant characteristic of Pseudovibrio strains is the production of secondary metabolites, which has been reported in many studies and will be discussed in detail below. Over the last decade there has been a considerable increase in the number of studies relating to the antimicrobial activity of a variety of bioactive compounds by Pseudovibrio spp. These studies highlight that this genus has the potential to be a particularly promising source of novel metabolites. Two families of enzymes, i.e., polyketide synthases (PKS) and non-ribosomal peptide synthetases (NRPS), and their hybrids (PKS/NRPS) are of particular importance in the production of various secondary metabolites, many of which are important/natural products, across a wide range of microorganisms. Analysis of the presence of $P K S$ and NRPS genes is often employed as a means of determining the likelihood that a microorganism has the potential to produce new bioactive compounds. For example, of the four Pseudovibrio cultures by Kennedy et al. [32] from the marine sponge H. simulans, two of which had 99\% 16S rRNA gene identity match to $P$. ascidiaceicola F10102., three were found to contain both putative $P K S$ and NRPS genes, suggesting a high potential for secondary metabolite 
production. In 2009, this group assessed the bioactivity of these Pseudovibrio bacteria [19]. The three Pseudovibrio strains, PV1, PV2, PV4, that contained PKS and NRPS genes exhibited antimicrobial activity against methicillin-resistant $S$. aureus, B. cereus, E. coli and B. subtilis. Interestingly, Pseudovibrio strain PV3 which did not contain PKS and NRPS genes, did not show antimicrobial activity against the target strains [19].

The presence of PKS and NRPS genes that might be involved in the production of secondary metabolites by sponge-associated microorganisms was also investigated in a study by Graça et al. [25]. In agreement with previous studies [33], it was found that the majority of bioactive bacteria in which PKS-I and NRPS genes were detected were Pseudovibrio. More specifically, Graça et al. found that of the 212 bacteria isolated from the marine sponge E. discophorus, 31\% produced antimicrobial compounds. Of these 66 bioactive-producing isolates, the most bioactive genus was Pseudovibrio (47\%) with bioactivity observed against B. subtilis ATCC6633, S. aureus MRSA and Aliivibrio fischeri CECT 524 [25]. This high level of activity within the genus has also been reported by Flemer et al. 2011 [34]. In that case out of the thirty Pseudovibrio strains isolated, 27 (90\%) exhibited antimicrobial activity against at least two of three clinically relevant bacteria strains tested i.e., E. coli NCIMB 12210, B. subtilis IA40, and S. aureus NCIMB 9518 [34]. The bioactivity profiles observed indicated the production of different antimicrobial compounds and again highlighted the broad range of activities associated with strains from this genus. This team also studied bioactive bacteria from the marine sponges A. fucorum and E. major [29]. In this instance, from the 409 bacterial strains isolated from both sponges and tested for antifungal and antibacterial activity, all of the strains exhibiting antibacterial activity were Pseudovibrio spp. More specifically, eight out of twelve Pseudovibrio strains isolated demonstrated activity. This activity was observed against at least one of the three targets employed, i.e., the aforementioned E. coli NCIMB 12210 as well as B. subtilis IE32 and S. aureus NC000949 [29].

Particularly broad spectrum activity by Pseudovibrio strains was demonstrated by Santos et al. [28]. Pseudovibrio strain Pm31 isolated from the sponge P. magna, strain Ca31 from C. aurea and strain Mm37 from Mycale microsimatosa demonstrated stable antimicrobial activity against Gram-positive targets Corynebacterium fimi NCTC 7547, Enterococcus faecium ATCC 19434, Enterococcus faecalis V583 (vancomycin), E. faecalis 5AE (vancomycin), S. aureus ATCC 29213, S. aureus 42AE (MRSA), S. aureus 559a (community-associated MRSA), Staphylococcus epidermidis ATCC 12228, S. epidermidis 57s (ampicillin, ciprofloxacin, penicillin, tetracycline), Staphylococcus haemolyticus ATCC 2997, S. haemolyticus 109s (ampicillin, gentamicin, oxacillin, penicillin), Staphylococcus hominis ATCC 27844, and against Gram-negative Acinetobacter calcoaceticus 56AE, E. coli 54 AE (ampicillin, chloramphenicol, trimethoprim/sulfamethoxazole, tetracyline), P. aeruginosa ATCC 27853, P. aeruginosa 3AE (aztreonam, piperacillin/tazobactam), and Salmonella enterica 4AE. It was noted that although activity was seen against both Gram-positive and Gram-negative target strains, the Pseudovibrio strains were more effective against Gram-positive bacteria. Tests to characterize the bioactive compound produced by the Pseudovibrio strains showed that the substances were resistant to the action of all proteolytic enzymes tested suggesting that these antimicrobial substances are not ribosomal proteins. Biofilm production by the isolated strains was observed and was particularly apparent when strains Pm31 and Mm37 were studied [28]. It has been hypothesized that the ability to 
produce antibacterial compounds combined with an enhancement in biofilm formation may give bacteria a selective advantage and possible dominance over other surface-attached bacteria [35].

O'Halloran et al. [33], referred to briefly above, also demonstrated broad spectrum activity from among a population of 73 Pseudovibrio isolates from the marine sponges A. dissimilis, P. boletiformis and $H$. simulans. This involved an initial screen using deferred antagonism assays from which it was revealed that 62 isolates $(84.9 \%)$ demonstrated antimicrobial activity against at least one of the indicator strains tested. The majority of the isolates showed activity against E. coli $(58 ; 79.5 \%)$, S. Typhimurium (54; 74\%), B. subtilis (49; 67.1\%), S. aureus (54; 74.0\%), MRSA (48; 65.8\%), vancomycin intermediate $S$. aureus (VISA) (45; 61.6\%), hVISA (47; 64.9\%), C. perfringens $(60 ; 82.2 \%)$ and $C$. difficile $(55 ; 75.3 \%)$. Activity was also observed against Yersinia enterocolitica (1; 1.4\%), B. cereus $(4 ; 5.5 \%)$, E. faecium (6;8.2\%), vancomycin-resistant Enterococcus (VRE) $(1 ; 1.4 \%)$ and L. monocytogenes $(2 ; 2.7 \%)$. Fourteen different antimicrobial activity spectra were identified suggesting and that the Pseudovibrio spp. may be producing a number of different antimicrobial compounds. The Pseudovibrio isolates were also screened for the presence of $P K S$ genes, using degenerate PCR, with keto synthase gene fragments being found in all 73 isolates.

Although secondary metabolite production and antimicrobial activity has been shown in many Pseudovibrio-related studies, in many cases the corresponding compounds have not been the focus of further analysis. However, some studies have characterised the relevant bioactive compounds. In one case, isolate Z143, a bacterium from a Philippine tunicate which had 100\% 16S rRNA gene similarity with the $P$. denitrificans type strain DN34 was reported in 2007 by Sertan de-Guzman [15] as the first $\alpha$-proteobacterium to produce the red pigment heptylprodigiosin (Figure 1A) also known as 16-methyl-15-heptyl-prodiginine, which shows anti-Staphylococcus aureus activity. Vizcaino et al. [21] revealed the production of a novel polypeptide, pseudovibrocin, which was isolated from three unique coral-derived bacteria with $99 \% 16 \mathrm{~S}$ rRNA gene similarity to P. denitrificans that were capable of inhibiting Gram-positive and Gram-negative bacteria. An acetone extract of the associated cell-free supernatant was found to inhibit Kocuria rhizophila and a methanol extract inhibited B. subtilis, Vibrio harveyi and $V$. coralliilyticus. High-performance liquid chromatography analysis of the methanol extract suggested the presence of at least two antibiotics, one of which shown to be pseudovibrocin. Geng and Belas [16] studied the biosynthesis of tropodithietic acid (TDA), a tropolone antibiotic, by a number of strains. In addition to other members of the Roseobacteracea family, i.e., Silicibacter sp. TM1040 and Phaeobacter gallaeciensis (both genera known to be TDA producers), Pseudovibrio sp. JE062, previously isolated by Enticknap et al. [24] was also found to be a TDA producer. The twelve genes required for TDA biosynthesis in strain JE062 were identified by transposon insertion mutagenesis and the organization of a number of the associated genes, $t d a A-F$, was found to be identical to that of the other bacteria in this study. The production of TDA by another Pseudovibrio sp., strain D323 (Figure 1B) has also been reported by Penesyan et al. [23]. This marine epiphytic strain was 99\% 16S rRNA gene identical to P. ascidiaceicola (Genbank Acc. \#AB175663) and exhibited antimicrobial activity against target strains from the phyla Alphaproteobacteria, Gammaproteobacteria, Bacteroidetes, Firmicutes and Actinobacteria. The authors in particular noted that TDA produced by D323 was highly active against Nautella sp. R11, which causes disease in a marine seaweed Delisea pulchra, thereby supporting the hypothesis that these host-associated bacteria serve as a defence against potential pathogenic surface colonisers. 
Genome-based methods such as comparative bacterial genomics [36] and "genome scanning" of sequenced genomes of natural-product-producing bacteria [37] can also lead to valuable information on the diversity of bacterial species and can lead to bioactive product discovery. In this regard it is relevant that Bondarev et al. [38] carried out analysis of the genomes of two Pseudovibrio strains, JE062 and FO-BEG1, that originated from the coast of Florida. At the time of writing, strain FO-BEG1 is the only Pseudovibrio for which a fully sequenced closed genome sequence has been reported.

Figure 1. Structures of Pseudovibrio-related antimicrobial compounds [39]: (A) Heptylprodigiosin; (B) Tropodithietic acid.

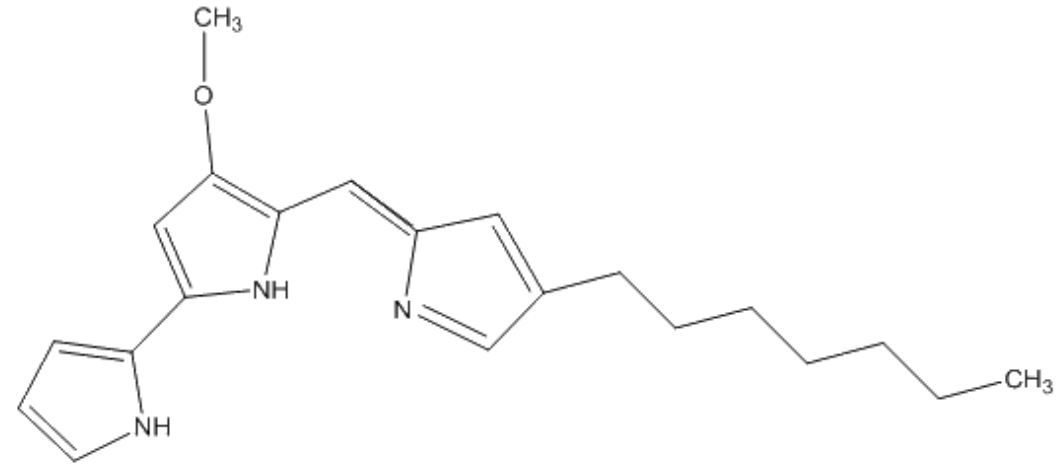

A

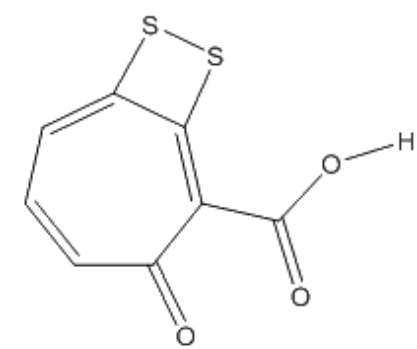

B

Genes involved in the biosynthesis of TDA were detected in FO-BEG1, and it was confirmed through culture-based methods that the strain is indeed a TDA producer. Although TDA production has been reported previously by other Pseudovibrio sp. [23,40], it is not clear how widely distributed this trait is. However, our own analysis of nine antimicrobial producing Pseudovibrio strains reveals the absence of TDA gene clusters from seven of these strains, indicating that this cluster may not be widely distributed [41]. Even in situations where the cluster is present, it is notable that culture conditions can impact on the production of TDA [42]. Indeed, TDA production has been detected during bacterial growth under static conditions [38], but not during incubation under agitation in broth, except for a brief period at approximately 10 hours after inoculation [16]. Another notable feature of the Bondarev study was the identification of genes predicted to encode a hybrid NRPS-PKS system in strain FO-BEG1, which resembled those previously associated with members of the Enterobacteriaceae [43]. More specifically, this cluster corresponds to a $50 \mathrm{~kb}$ genomic island which is architecturally similar to a NRPS-PKS system reported by Nougayrède et al. [44] and determined to be colibactin (an E. coli metabolite). Similarities in the architecture between these two NRPS-PKS systems led to the suggestion that the product of the Pseudovibrio FO-BEG1 cluster is colibactin. Again, it is not clear to what extent this cluster is distributed among Pseudovibrio sp. so we have employed a previously designed PCR primer set [44] to determine the distribution of the NRPS-PKS system within our nine Pseudovibrio strains, and detected the presence of these genes in all nine strains [41]. Romano et al. [45] also demonstrated the astonishing diversity of the exo-metabolome (extracellular metabolites) of strain FO-BEG1 and the drastic effect that phosphate limitation can have on its composition. More specifically, results showed that low phosphate concentrations can induce the production of secondary metabolites in Pseudovibrio FO-BEG1. Under phosphate limitation, a higher production of phenolic 
and polyphenolic compounds was also observed by Romano et al. [45] when cells entered stationary phase. It was suggested by the authors that some of these compounds may be tropone derivatives, of which TDA is an example, which are commonly produced by bacteria of the Roseobacter clade and can have antibacterial activity. Indeed members of the Roseobacter clade produce TDA in addition to an uncharacterised yellow pigment, which may be the same pigment produced in this study by Pseudovibrio under phosphate-limited conditions and entering stationary phase. In addition, several masses were predicted to correspond to cyclic dipeptides that resemble antimicrobials produced by Roseobacter strains isolated from marine sponges. Given the phylogenetic and physiological similarity between Roseobacter and Pseudovibrio bacteria, the authors reasoned that Pseudovibrio may also release such compounds into the medium [45].

Genomic analysis of Pseudovibrio FO-BEG1 (Figure 2) and JE062 has also revealed the potential for a diverse array of metabolic abilities within both strains [43].

Figure 2. Analysis of Pseudovibrio FO-BEG1 via antiSmash showing (A) Terpene type gene cluster; (B) Non-ribosomal peptide synthetases (NRPS)-polyketide synthases (PKS) cluster; (C) Putative bacteriocin 1; (D) Putative bacteriocin 2 ; and (E) T3pks-T1pks cluster on plasmid.

\section{Gene cluster description}

Gene Cluster 1. Type = terpene. Location: 3453932 - 3474792 nt. Click on genes for more information.

Show pHMM detection rules used

A

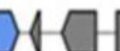

\section{Gene cluster description}

Gene Cluster 2. Type = nrps-t1pks. Location: $3555849-3639763$ nt. Click on genes for more information.

Show pHMM detection rules used

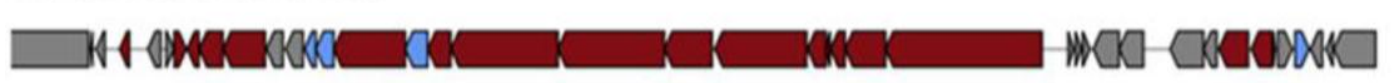

\section{Gene cluster description}

Gene Cluster 3. Type = bacteriocin. Location: $3641470-3652363 \mathrm{nt}$. Click on genes for more information .

Show PHMM detection rules used

\section{Gene cluster description}

Gene Cluster 4. Type = bacteriocin. Location: $5153040-5163942 \mathrm{nt}$. Click on genes for more information.

Show pHMM detection rules used

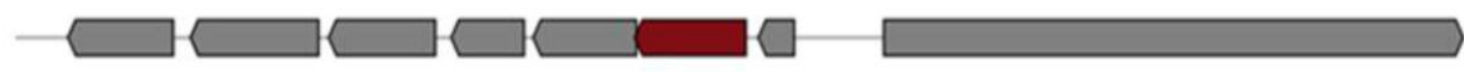

\section{Gene cluster description}

Gene Cluster 1. Type = t3pks-t1pks. Location: $201027-264565$ nt. Click on genes for more information .

Show pHMM detection rules used

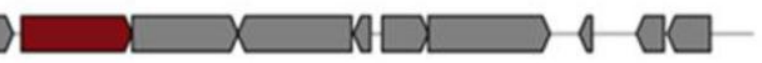

Legend:

biosynthetic genes $\square$ transport-related genes $\square$ regulatory genes $\square$ other genes 
Analysis revealed the presence of genes predicted to be involved in carbohydrate, lipid, fatty acid, lipopolysaccharide, sugar and glycan metabolism. Pathways involved in terpenoid, sterol, cofactor and vitamin and polyamine biosynthesis have also been identified, as have genes predicted to be involved in the biosynthesis of secondary metabolites such as monolignol, flavanone, flavonoid and paspaline [46]. Our own unpublished analysis [47], of Pseudovibrio FO-BEG1 via antiSmash (antibiotics and Secondary Metabolite Analysis Shell) and BAGEL (prediction of bacteriocins in prokaryotes) have highlighted a number of clusters of interest. More specifically, antiSmash highlighted a terpene type gene cluster (Figure 2A) and two putative bacteriocin clusters (Figure 2C,D), in addition to the previously mentioned NRPS-PKS system (Figure 2B) on the chromosome and a type T3pks-T1pks cluster on the plasmid (Figure 2E) [47]. BAGEL also highlighted loci of significance related to putative bacteriocins [48].

Ultimately, although it is evident from the literature that Pseudovibrio sp. can possess broad range antimicrobial activity, in many cases the basis for this activity has not been further analysed. Therefore the opportunity to identify novel bioactive compounds exists. As previously mentioned, culture conditions can have a significant effect on the production of antimicrobials, which is often tightly regulated, and must be taken into consideration when designing experiments (Figure 3) in order to establish the optimum conditions for maximum production of bioactives. The schematic diagram below outlines the procedures currently underway and being employed to study a number of Pseudovibrio strains and which may prove fruitful for others.

Figure 3. Schematic diagram outlining relevant experimental procedures which may lead to the identification of novel bioactive molecules.

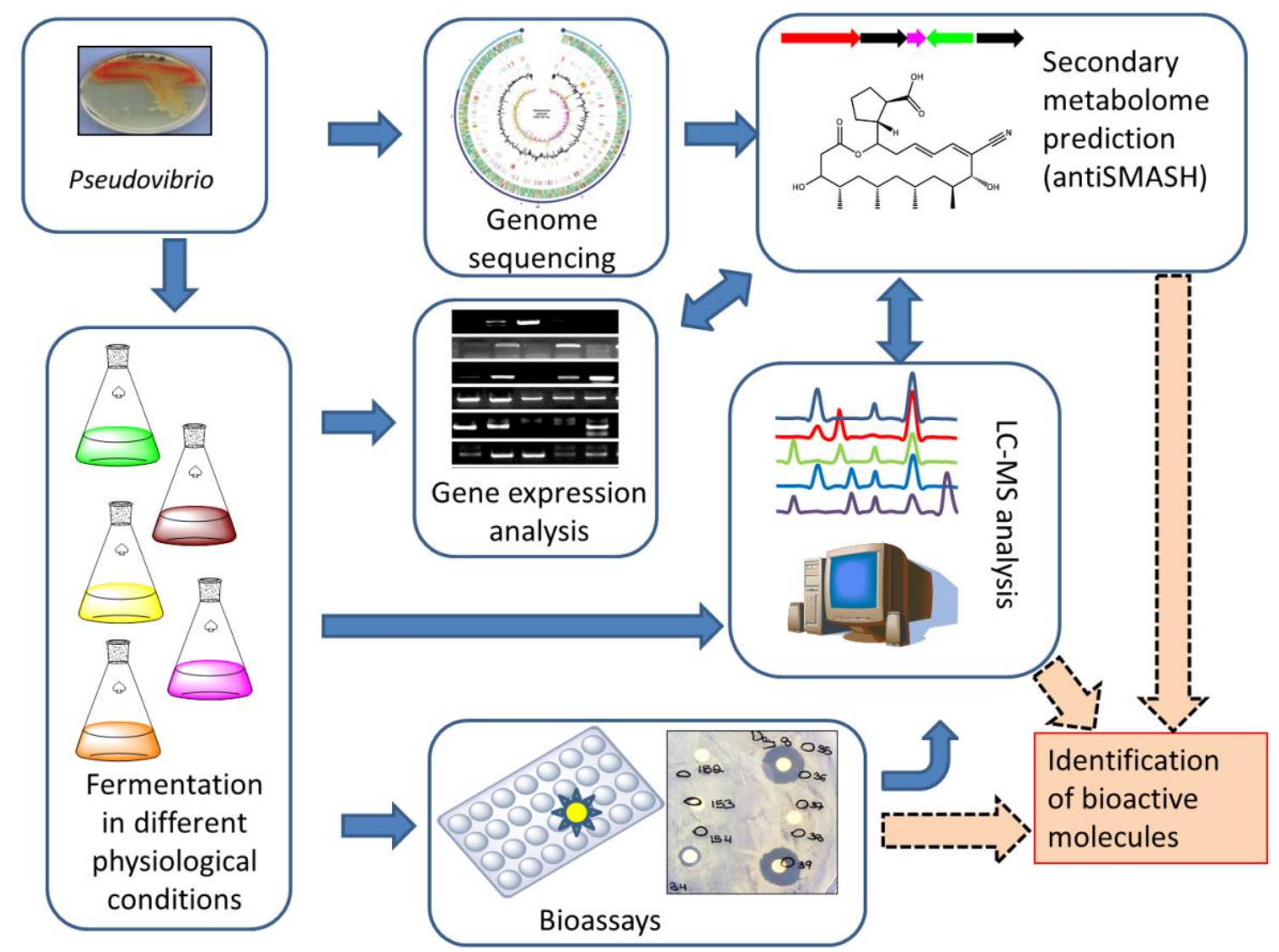


In addition to the identification of potentially novel bioactive compounds, the use of these approaches can allow one to demonstrate the spectrum of antimicrobial activity of the strains, facilitate the identification of putative bioactive clusters and to carry out comparative genomics.

\section{Conclusions}

Antibiotic resistance among pathogenic microorganisms is becoming ever more common. Unfortunately, the development of new antibiotics which may combat these pathogens has decreased. Natural sources has provided, and can continue to provide, a diverse range of compounds for drug development and many of these biologically active natural products are of microbial origin. As the hunt for novel, natural and potent antibiotics continues, focus has recently shifted to the oceans for natural product discovery as the marine environment has revealed itself as the relatively untapped source of potent bioactives. In recent years, the marine-derived Pseudovibrio has been the focus of particular attention due to the dominance of the genus among host-associated microbial communities and its associated antimicrobial producing capabilities. More specifically, the potency, broad-spectrum and novelty of the compounds produced by these bacteria has highlighted this genus as a source of natural antimicrobial compounds which can potentially be employed to combat the prevalence of antibiotic resistant bacteria among the healthcare and food production sectors. Varying physiological growth conditions, gene expression and biological analysis, in addition to the knowledge gained through genome sequencing of members of the genus Pseudovibrio, may lead to the identification of genes involved in the production of secondary metabolites, optimum growth parameters and gene expression; eventually leading to the development of novel bioactives.

\section{Acknowledgments}

The authors are funded by the Department of Agriculture, Food and the Marine Food Institutional Research Measure (FIRM) (MabS project No. 11/f/009), the Beaufort Marine Biodiscovery Research award funded by the Irish Government under the National Development Plan (2007-2013) and the PharmaSea project funded by the EU Seventh Framework Program.

\section{Author Contributions}

This review was conceived, designed and written by Susan P. Crowley, Alan D. W. Dobson and Paul D. Cotter. All authors discussed the content of the review. The review was polished by authors: Fergal O'Gara and Orla O'Sullivan.

\section{Conflicts of Interest}

The authors declare no conflict of interest.

\section{References}

1. United State Department of Health and Human Services. Antibiotic Resistance Threats in the Unites States; Centers for Disease Control and Prevention: Atlanta, GA, USA, 2013. 
2. ECDC. Annual Epidemiological Report 2012; European Center for Disease Prevention and Control: Tomtebodavägen 11a, 17183, Stockholm, Sweden. Available Online: http://www.ecdc.europa.eu/en/publications/Annual-Epidemiological-Report-2012.pdf (accessed on 14 February 2014).

3. Kanerva, M.; Ollgren, J.; Hakanen, A.J.; Lyytikäinen, O. Estimating the burden of healthcare-associated infections caused by selected multidrug-resistant bacteria Finland, 2010. Antimicrob. Resist. Infect. Control 2012, 1, doi:10.1186/2047-2994-1-33.

4. Infectious Diseases Society of America. The $10 \times$ '20 initiative: Pursuing a global commitment to develop 10 new antibacterial drugs by 2020. Clin. Infect. Dis. 2010, 50, 1081-1083.

5. Talbot, G.H.; Bradley, J.; Edwards, J.E.; Gilbert, D.; Scheld, M.; Bartlett, J.G. Bad bugs need drugs: An update on the development pipeline from the antimicrobial availability task force of the infectious diseases society of America. Clin. Infect. Dis. 2006, 42, 657-668.

6. Penesyan, A.; Kjelleberg, S.; Egan, S. Development of novel drugs from marine surface associated microorganisms. Mar. Drugs 2010, 8, 438-459.

7. Penesyan, A.; Marshall-Jones, Z.; Holmstrom, C.; Kjelleberg, S.; Egan, S. Antimicrobial activity observed among cultured marine epiphytic bacteria refects their potential as a source of newdrugs. Fed. Eur. Microbiol. Soc. 2009, 69, 113-124.

8. European Science Foundation. A New Vision and Strategy for Europe; Marine Board: Ostend, Belgium, 2012.

9. Lam, K.S. Discovery of novel metabolites from marine actinomycetes. Curr. Opin. Microbiol. 2006, 9, 245-251.

10. Prudhomme, J.; McDaniel, E.; Ponts, N.; Bertani, S.; Fenical, W.; Jensen, P.; le Roch, K. Marine actinomycetes: A new source of compounds against the human malaria parasite. PLoS One 2008, doi:10.1371/journal.pone.0002335.

11. Hentschel, U.; Schmid, M.; Wagner, M.; Fieseler, L.; Gernert, C.; Hacker, J. Isolation and phylogenetic analysis of bacteria with antimicrobial activities from the Mediterranean sponges Aplysina aerophoba and Aplysina cavernicola. FEMS Microbiol. Ecol. 2001, 35, 305-312.

12. Viegelmann, C.; Margassery, L.; Kennedy, J.; Zhang, T.; OBrien, C.; O’Gara, F.; Morrisssey, J.; Dobson, A.; Edrada-Ebel, R. Metabolomic profiling and genomic study of a marine sponge-associated Streptomyces sp. Mar. Drugs 2014, 12, 3323-3351.

13. Prieto, M.L.; O’Sullivan, L.; Tan, S.P.; McLoughlin, P.; Hughes, H.; O’Connor, P.M.; Cotter, P.D.; Lawlor, P.G.; Gardiner, G.E. Assessment of the bacteriocinogenic potential of marine bacteria reveals lichenicidin production by seaweed-derived Bacillus spp. Mar. Drugs 2012, 10, 2280-2299.

14. Desriac, F.; Jégou, C.; Balnois, E.; Brillet, B.; le Chevalier, P.; Fleury, Y. Antimicrobial peptides from marine proteobacteria. Mar. Drugs 2013, 11, 3632-3660.

15. Sertan-de Guzman, A.A.; Bernardo, R.Z.; Neilan, B.A.; Elardo, S.P.; Mangalindan, G.C.; Tasdemir, D.; Ireland, C.M.; Barraquio, W.L.; Concepcion, G.P. Pseudovibrio denitrificans strain Z143-1, a heptylprodigiosin-producing bacterium isolated from a Philippine tunicate. FEMS Microbiol. Lett. 2007, 277, 188-196.

16. Geng, H.F.; Belas, R. Expression of tropodithietic acid biosynthesis is controlled by a novel autoinducer. J. Bacteriol. 2010, 192, 4377-4387. 
17. Thiel, V.; Imhoff, J.F. Phylogenetic identification of bacteria with antimicrobial activities isolated from Mediterranean sponges. Biomol. Eng. 2003, 20, 421-423.

18. Muscholl-Silberhorn, A.; Thiel, V.; Imhoff, J.F. Abundance and bioactivity of cultured sponge-associated bacteria from the mediterranean sea. Microb. Ecol. 2008, 55, 94-106.

19. Kennedy, J.; Baker, P.; Piper, C.; Cotter, P.D.; Walsh, M.; Mooij, M.J.; Bourke, M.B.; Rea, M.C.; O'Connor, P.M.; Ross, R.P.; et al. Isolation and analysis of bacteria with antimicrobial activities from the marine sponge Haliclona simulans collected from Irish waters. Mar. Biotechnol. 2009, 11, 384-396.

20. Fukunaga, Y.; Kurahashi, M.; Tanaka, K.; Yanavfbgi, K.; Yokota, A.; Harayama, S. Pseudovibrio ascidiaceicola sp. nov., isolated from ascidians (sea squirts). Int. J. Syst. Evol. Microbiol. 2006, 56, 343-347.

21. Vizcaino, M.; Moeller, P.; Morris, P. The Potential for the Marine Bacterium Pseudovibrio denitrificans to Produce Novel Antibiotics. Available Online: https://www.musc.edu/mbes-ljg/ MBESOpenHouse/2010/abstracts/Vizcaino-SROH_July_16_2010.pdf (accessed on 30 March 2014).

22. Shieh, W.Y.; Lin, Y.T.; Jean, W.D. Pseudovibrio denitrificans gen. nov., sp. nov., a marine, facultatively anaerobic, fermentative bacterium capable of denitrification. Int. J. Syst. Evol. Microbiol. 2004, 54, 2307-2312.

23. Penesyan, A.; Tebben, J.; Lee, M.; Thomas, T.; Kjelleberg, S.; Harder, T.; Egan, S. Identification of the antibacterial compound produced by the marine epiphytic bacterium Pseudovibrio sp. D323 and related sponge-associated bacteria. Mar. Drugs 2011, 9, 1391-1402.

24. Enticknap, J.J.; Kelly, M.; Peraud, O.; Hill, R. Characterization of a culturable alphaproteobacterial symbiont common to many marine sponges and evidence for vertical transmission via sponge larvae. Appl. Environ. Microbiol. 2006, 72, 3724-3732.

25. Graca, A.P.; Bondoso, J.; Gaspar, H.; Xavier, J.R.; Monteiro, M.C.; de la Cruz, M.; Oves-Costales, D.; Vicente, F.; Lage, O.M. Antimicrobial Activity of Heterotrophic Bacterial Communities from the Marine Sponge Erylus discophorus (Astrophorida, Geodiidae). PLoS One 2013, 8, e78992.

26. Taylor, M.; Radax, R.; Seger, D.; Wagner, M. Sponge-associated microorganisms: Evolution, ecology, and biotechnological potential. Microbiol. Mol. Biol. Rev. 2007, 71, 295-347.

27. Esteves, A.I.; Hardoim, C.C.; Xavier, J.R.; Goncalves, J.M.; Costa, R. Molecular richness and biotechnological potential of bacteria cultured from Irciniidae sponges in the north-east Atlantic. FEMS Microbiol. Ecol. 2013, 85, 519-536.

28. Santos, O.C.; Pontes, P.V.; Santos, J.F.; Muricy, G.; Giambiagi-deMarval, M.; Laport, M.S. Isolation, characterization and phylogeny of sponge-associated bacteria with antimicrobial activities from Brazil. Res. Microbiol. 2010, 161, 604-612.

29. Margassery, L.M.; Kennedy, J.; O’Gara, F.; Dobson, A.D.; Morrissey, J.P. Diversity and antibacterial activity of bacteria isolated from the coastal marine sponges Amphilectus fucorum and Eurypon major. Lett. Appl. Microbiol. 2012, 55, 2-8.

30. Hosoya, S.; Yokota, A. Pseudovibrio japonicus sp. nov., isolated from coastal seawater in Japan. Int. J. Syst. Evol. Microbiol. 2007, 57, 1952-1955. 
31. O’Halloran, J.A.; Barbosa, T.M.; Morrissey, J.P.; Kennedy, J.; Dobson, A.D.; O’Gara, F. Pseudovibrio axinellae sp. nov., isolated from an Irish marine sponge. Int. J. Syst. Evol. Microbiol. 2013, 63, 141-145.

32. Kennedy, J.; Codling, C.E.; Jones, B.V.; Dobson, A.D.; Marchesi, J.R. Diversity of microbes associated with the marine sponge, Haliclona simulans, isolated from Irish waters and identification of polyketide synthase genes from the sponge metagenome. Environ. Microbiol. 2008, 10, 1888-1902.

33. O’Halloran, J.A.; Barbosa, T.M.; Morrissey, J.P.; Kennedy, J.; O’Gara, F.; Dobson, A.D. Diversity and antimicrobial activity of Pseudovibrio spp. from Irish marine sponges. J. Appl. Microbiol. 2011. 110, 1495-1508.

34. Flemer, B.; Kennedy, J.; Margassery, L.M.; Morrissey, J.P.; O’Gara, F.; Dobson, A.D. Diversity and antimicrobial activities of microbes from two Irish marine sponges, Suberites carnosus and Leucosolenia sp. J. Appl. Microbiol. 2011, 112, 289-301.

35. Bruhn, J.B.; Gram, L.; Belas, R. Production of antibacterial compounds and biofilm formation by Roseobacter species are influenced by culture conditions. Appl. Environ. Microbiol. 2007, 73, 442-450.

36. Fernández-Gómez, B.; Fernàndez-Guerra, A.; Casamayor, E.O.; González, J. M.; Pedrós-Alió, C.; Acinas, S.G. Patterns and architecture of genomic islands in marine bacteria. BMC Genomics 2012, 13, doi:10.1186/1471-2164-13-347.

37. Zhao, X.Q. Genome-based studies of marine of microorganisms to maximize the diversity of natural products discovery for medical treatments. Evid.-Based Complement. Altern. Med. 2011, 2011, doi:10.1155/2011/384572.

38. Bondarev, V.; Rcchter, M.; Romano, S.; Piel, J.; Schwedt, A.; Schulz-Vogt, H.N. The genus Pseudovibrio contains metabolically versatile bacteria adapted for symbiosis. Environ. Microbiol. 2013, 15, 2095-2113.

39. CambridgeSoft Corporation, ChemBioDraw Software. 2012. PerkinElmer, 100 Cambridge Park Drive, Cambridge, MA 02140. Available online: http://www.cambridgesoft.com/ Ensemble_for_Biology/ChemBioDraw/Default.aspx. Analysis and visualisation of molecular structures (Accessed on 23 November 2014).

40. Berger, M.; Neumann, A.; Schulz, S.; Simon, M.; Brinkhoff, T. Tropodithietic acid production in Phaeobacter gallaeciensis is regulated by $N$-acyl homoserine lactone-mediated quorum sensing. J. Bacteriol. 2011, 193, 6576-6585.

41. Crowley, S.P.; O’Gara, F.; O’Sullivan, O.; Dobson, A.D.W.; Cotter, P.C. Pseudovibrio isolates with anti-Salmonella activity. In progress.

42. Geng, H.; Bruhn, J.B.; Nielsen, K.F.; Gram, L.; Belas, R. Genetic dissection of tropodithietic acid biosynthesis by marine roseobacters. Appl. Environ. Microbiol. 2008, 74, 1535-1545.

43. Putze, J.; Hennequin, C.; Nougayrede, J.P.; Zhang, W.L.; Homburg, S.; Karch, H.; Bringer, M.A.; Fayolle, C.; Carniel, E.; Rabsch, W.; et.al. Genetic structure and distribution of the colibactin genomic island among members of the family enterobacteriaceae. Infect. Immun. 2009, 77, 4696-4703. 
44. Nougayrède, J.P.; Homburg, S.; Taieb, F.; Boury, M.; Brzuszkiewicz, E.; Gottschalk, G.; Buchrieser, C.; Hacker, J.; Dobrindt, U.; Oswald, E. Escherichia coli induces DNA double-strand breaks in eukaryotic cells. Science 2006, 313, 848-851.

45. Romano, S.; Dittmar, T.; Bondarev, V.; Weber, R.J.M.; Viant, M.R.; Schulz-Vogt, H.N. Exo-Metabolome of Pseudovibrio sp. FO-BEG1 Analyzed by Ultra-High Resolution Mass Spectrometry and the Effect of Phosphate Limitation. PLoS One 2014, 9, e96038.

46. Genomes. Metabolic pathways-Pseudovibrio sp. FO-BEG1. Available online: http://www.genome.jp/kegg-bin/show_pathway?psf01100 (accessed on 20 August 2014).

47. Blin, K.; Medema, M.H.; Kazempour, D.; Fischbach, M.A.; Breitling, R.;Takano, E.; Weber, T. AntiSMASH 2.0-A versatile platform for genome mining of secondary metabolite producers. Nucleic Acids Res. 2013, 41, 204-212.

48. De Jong, A.; van Hijum, S.A.F.T.; Bijlsma, J.J.E.; Kok, J.; Kuipers, O.P. BAGEL: A web-based bacteriocin genome mining tool. Nucleic Acids Res. 2006, 34, 273-279.

(C) 2014 by the authors; licensee MDPI, Basel, Switzerland. This article is an open access article distributed under the terms and conditions of the Creative Commons Attribution license (http://creativecommons.org/licenses/by/4.0/). 